DOI: $10.17805 /$ zpu.2017.2.23

\title{
119-й сонет Шекспира как автокоммуникация
}

\author{
В. С. ФЛОРОВА
}

МОСКОВСКИЙ ПЕДАГОГИЧЕСКИЙ ГОСУДАРСТВЕННЫЙ УНИВЕРСИТЕТ

В статье рассматривается 119-й сонет У. Шекспира как автокоммуникация. Здесь слово поэта рождается на стыке «речи для себя», т. е. внутренней, в значительной степени спонтанной, и внешней речи. Яркой особенностью автокоммуникации является абсолютно идентичный объем памяти адресанта и адресата: иначе говоря, такой текст совершенно не нацелен на передачу информации. 119-й сонет выступает не в виде рассказа о некотором событии, а выполняет качественно иную функцию, а именно истолкования, новой интерпретации уже заведомо известного.

Отсюда следует вторая важная особенность: наличие в тексте особого вида редукции. В автокоммуникации наблюдаются фрагментарность, отрывочность, стремление к сокращению подлежащего-темы. Событие не пересказывается, однако новые выводы субъекта о себе самом на нем основываются и на него намекают. Л. С. Выготский назвал эту тенденцию к сокращению подлежащего предикацией. Предикация связана, в частности с тем, что никакая автокоммуникация не является самообусловленной: для нее всегда обязательно наличие внешнего импульса, сдвигающего ситуацию, который, однако, при обращении к самому себе остается как бы «за кадром» речи.

Названные характерные черты автокоммуникации очень ярко проявляются во вступительном образе 119-го сонета: множество задействованных в нем значений как бы «стянуты» в один емкий комбинированный смысл, при этом основа образа (подлежащее) восстанавливается лишь гипотетически. Структура всего текста также определена ситуацией обращения к самому себе: внешне двухчастная, она на деле является трехчастной, но основное событие стихотворения опущено, редуцировано почти до полной паузы. В статье делается вывод, что понимание 119-го сонета Шекспира как автокоммуникации позволяет лучше понять его существенные особенности.

Ключевые слова: У. Шекспир; сонет; автокоммуникация; предикация; лирический герой; автор; событие; сюжет; фабула; пространство; время

\section{ВВЕАЕНИЕ}

$\mathrm{B}$ любом лирическом стихотворении слово поэта рождается на стыке двух противоположных дискурсов: "речи для себя» (т. е. внутренней) и «речи Аля другого» (внешней) (см.: Ковтунова, 1986). Однако в каждом конкретном случае позиция автора может смещаться либо в одну, либо в другую сторону, в пределе превращая стихотворение или в «закрытый» интимный текст, или в произведение, прямо предназначенное для публичного чтения. «Сонеты» Шекспира, как правило, предполагают наличие хотя бы узкого круга читателей. Тем больший интерес вызывают тексты, в которых адресант и адресат совпадают, т. е. тот случай, когда лирический герой обращается лишь к себе самому. Сонет такого типа представляет собой чистую автокоммуникацию, и одним из ее ярких примеров выступает Q 1191.

\section{ОСОБЕННОСТИ АВТОКОММУНИКАЦИИ}

Приведем текст сонета в оригинале (Shakespeare, 2002: 619) и своем подстрочном переводе.

1. What potions have I drunk of Siren tears,

2. Distilled from limbecks foul as hell within,

3. Applying fears to hopes, and hopes to fears,

Что за зелья выпил я из слез Сирены, Нацеженные из перегонных кубов, мерзостных, как ад изнутри, Прилагая страхи к надеждам и надежды к страхам, 
4. Still losing when I saw myself to win!

5. What wretched errors hath my heart committed,

6. Whilst it hath thought itself so blessed never! Пока оно полагало себя блаженным, как ни-

7. How have mine eyes out of their spheres been fitted,

8. In the distraction of this madding fever!

9. O benefit of ill! now I find true

10. That better is by evil still made better;

11. And ruined love, when it is built anew,

12. Grows fairer than at first, more strong, far greater.

13. So I return rebuked to my content,

14. And gain by ill thrice more than I have spent. когда!

Тогда теряя, когда я видел себя выигрывающим!

Что за скверные ошибки совершало мое сердце,

Как мои глаза выступали из орбит

В самозабвении этой безумной лихорадки!

О благодеянье зла! теперь я нахожу истиной, Что лучшее от злого делается еще лучше, И разбитая любовь, когда она восстановлена заново,

Становится прекраснее, чем вначале, гораздо сильнее, более великой.

Так я возвращаюсь, порицаемый, к своей отраде И получаю благодаря злу втрое больше, чем я растратил.

Композиционно Q 119 четко делится на две части по временному признаку: начало сонета - прошлое (первый и второй катрены), конец сонета - настоящее (третий катрен и двустишие). Прошлое описывается лирическим героем как наваждение: он был словно отравлен колдовским зельем, а его целостное «я» распадалось на части, что выражено передачей способности самостоятельного действия от всего «я» отдельным его частям с усилением в финале: я выпил зелье - мое сердие ошибалось, - мои глаза bыступали из орбит. Переход от прошлого к настоящему совершается с помощью эмоционального восклицания, выражающего чувство потрясения героя: $O$ benefit of ill! («О благодеянье зла!»). Это эмоциональный перелом. Настоящее сонета - не обычное эпическое настоящее, имеющее достаточно большую временную протяженность, а именно текущий момент, в который герой и осознает все с ним происходящее, благодаря чему он способен определить как «прошлое» свое недавнее наваждение. Но, потрясенный настигшим его озарением, лирический герой еще полностью на нем сосредоточен и не может перейти к более широким обобщениям. Сейчас он живет только минутой, о которой и говорит, обращаясь не к какому-либо постороннему аАресату, а к себе самому. Такая автокоммуникация прежде всего означает, что в Q 119 нет «завершающего контекста автора», если воспользоваться термином М. М. Бахтина (Бахтин, 2003: 88). Здесь автор слит с героем и видит не далее его.

Автокоммуникация по определению предполагает абсолютно идентичный объем памяти адресанта и адресата, т. е. она совершенно не нацелена на простую передачу сообщения. Как отмечал Ю. М. Аотман, «если схема коммуникации “Я - ОН" подразумевает передачу информации при сохранении константности ее объема, то схема

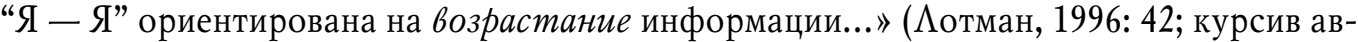
тора. - В. Ф.). «В системе "Я - Я" носитель информации остается тем же, но сообщение в процессе коммуникации переформулируется и приобретает новый смысл» (там же: 25). Аюбые факты и сведения уже заведомо известны субъекту, так как он сам является их носителем. Таким образом, роль сообщения здесь сведена к минимуму, и весь текст выступает не в виде рассказа о некотором событии, а выполняет качественно иную функцию. Эта функция есть функция истолкования, новой интерпретации уже заведомо известного, т. е. функция переосмысления внешних (или ставших 
внешними) событий в новом внутреннем контексте. Такое переосмысление всегда приводит к ценностной переориентации адресата-адресанта, к внутренней перестройке самого говорящего «я». Поэтому главный смысл и назначение такого типа текста не повествование, а эмоииональная рефлексия, самопереживание, самоосознание. Отсюда следует еще одна важная особенность: наличие в тексте особого вида редукции. Последнее особенно сближает поэтическую речь с внутренней. $\Lambda$. С. Выготский отмечал: «...первой и главнейшей особенностью внутренней речи является ее совершенно особый синтаксис. <...> Эта особенность заключается в кажущейся отрывочности, фрагментарности, сокращенности внутренней речи по сравнению с внешней» (Выготский, 1934: 292). «Мы всегда в курсе нашей внутренней ситуации. Тема нашего внутреннего диалога всегда известна нам. Мы знаем, о чем мы думаем. Подлежащее нашего внутреннего суждения всегда наличествует в наших мыслях» (там же: 301). Очевидно, что поэту незачем излагать себе самому те факты личного опыта, влияние которых предопределило изменение состояния его сознания; подробный их пересказ был бы психологически излишен и семантически затруднен, поскольку их прежнее значение в ходе переосмысления заменяется на новое. Поэтому в автокоммуникации наблюдается редукция личного опыта и жизненных событий-импульсов: они не пересказываются, однако новые выводы субъекта о себе самом основываются на них и на них намекают. А. С. Выготский назвал эту особенность предикащией, т. е. тенденцией «к сокращению фразы и предложения в направлении сохранения сказуемого и относящихся к нему частей предложения за счет опускания подлежащего и относящихся к нему слов» (там же: 293). Под подлежащим здесь имеется в виду логическая тема или ситуация, вызвавшая внутреннюю речь. Адресанту автокоммуникации достаточно только отсылок к памяти адресата в силу полного тождества ее объема.

К этому надо добавить еще одно замечание: никакая автокоммуникация не является исключительно самообусловленной, т. е. для нее всегда обязательно наличие внешнего импульса: «Передача сообщения по каналу “Я — Я" не имеет имманентного характера, поскольку обусловлена вторжением извне некоторых добавочных кодов и наличием внешних толчков, сдвигающих контекстную ситуацию» (Иотман, 1996: 26). Однако невозможно описывать «внешний импульс» в терминах жизни лирического героя; «внешний импульс» применим только к внешнему опыту автора. Из сказанного можно сделать вывод: текст Q 119 является порождением влияния какой-то внешней ситуации из дичного опыта поэта. К этому наблюдению мы еще вернемся.

\section{АВТОР И ГЕРОЙ В СОНЕТЕ-АВТОКОММУНИКАЦИИ}

Автор - это ценностный центр упорядочивания художественной реальности. Его отличает особая позиция вненаходимости. Однако, поскольку Q 119 представляет собой автокоммуникацию, то автор оказывается слит с героем: «...герой завладевает автором. Эмоционально-волевая предметная установка героя, его познавательно-этическая позиция в мире настолько авторитетны для автора, что он не может не видеть предметный мир только глазами героя... автор не может найти убедительной и устойчивой ценностной точки опоры вне героя» (Бахтин, 2003: 99). Однако сказанное не означает, что автор отсутствует вообще. Он, разумеется, есть, и мы уже обнаружили его присутствие в виде порождающего текст импульса. Автор присутствует в тексте и иным образом: как создатель формально-эстетического уровня бытия. Здесь полностью проявляются те особенности чистой лирики, о которых говорит М. М. Бахтин: «В лирике автор наиболее формалистичен, т. е. творчески растворяется во внешней 
звучащей и внутренней живописно-скульптурной и ритмической форме, отсюда кажется, что его нет...» (там же: 77). Но «конечно, раздвоение на героя и автора здесь есть», однако «это отношение носит лишь особый характер здесь - оно успокоенножеланно, герой не боится и не стыдится быть выраженным... автору не нужно с ним бороться...» (там же: 82). Иначе говоря, в чистой лирике переживания героя являются непосредственным предметом формально-эстетической реакции автора. Автор проявляется в текстах этого типа как создатель синтагматического ряда и метрической упорядоченности. В этом смысле можно говорить об особой әстетической значимости для автора описываемого содержания.

Ценностная эмоциональная реакция лирического героя, как правило, выражается в ритмико-интоначионной структуре стихотворения, автору же принадлежит метрическая и логико-синтаксическая модель построения содержания. Здесь следует отметить, что синтаксис Шекспира вообще отличается исключительной логичностью: как бы ни было стихотворение перегружено эмоционально, его строение всегда демонстрирует четкий поступательный ход мысли. При взгляде на Q 119 это становится очевидно. Его синтаксическая структура может быть представлена следующей схемой, расположенной на временной шкале: описание прошлого, пороговое время (опущенное подлежащее-ситуация) и описание настоящего:

\begin{tabular}{|c|c|c|}
\hline 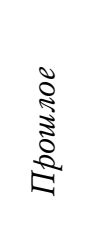 & $\begin{array}{l}\text { What potions have I drunk... (Что за зелья я выпил...) } \\
\hookrightarrow \text { Applying... Still losing when... (Прилагая... Теряя тогда, когда...) } \\
\text { What wretched errors hath my heart committed... (Что за скверные } \\
\text { ошибки совершало мое cepдце...) } \\
\text { How have mine eyes out of their spheres been fitted... (Как мои глаза } \\
\text { выступали из орбит...) }\end{array}$ & $\begin{array}{l}\text { 1-й катрен } \\
+ \\
2 \text {-й катрен }\end{array}$ \\
\hline 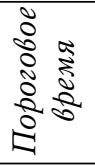 & O benefit of ill! (О благодеянье зла!) & \\
\hline 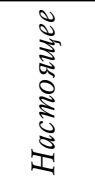 & $\begin{array}{l}\text { now I find true (Теперь я нахожу истиной) } \\
\hookrightarrow \text { That better... And ruined love... (что лучшее... И разбитая } \\
\text { любовь...) } \\
\text { So I return... And gain... (Так я возвращаюсь... И обретаю...) }\end{array}$ & $\begin{array}{l}3 \text {-й катрен } \\
+ \\
\text { двустишие }\end{array}$ \\
\hline
\end{tabular}

На схеме видно, что структура сонета в действительности является трехчастной, но центральная часть - перелом, пороговое время, - в сущности, выведена за пределы непосредственного содержания, редуцирована. Это не просто эмоциональное восклицание героя, это указание на опущенную импульсную ситуацию из внешнего опыта автора. Она, в сущности, и является главной темой, логическим подлежашим Q 119. «Избыточность» в сравнении с ней описаний прошлого и настоящего вызвана предикативностью внутреннего дискурса. «Сокращение мысли за счет пропуска наименования предмета речи (знак внутренней речи), - пишет об этом И. И. Ковтунова, - сочетается с развертыванием мысли за счет варьирования предикатов, образования рядов предикатов, кружения вокруг одной темы... Развернутый ряд сообщений, с одной стороны, моделирует внутренние поиски знания, стремление постигнуть предмет путем присвоения ему все новых признаков, при помощи все новых уподоблений, 
с другой стороны, такой ряд - структура, организуемая как “речь для других” (Ковтунова, 1986: 8; курсив автора. - В. Ф.). В «предикативных» частях сонета наблюдается параллелизм: первый катрен параллелен третьему, второй - заключительному двустишию, тогда как содержательно они противопоставлены: первый катрен содержит вопрос героя к себе самому о происходившем с ним, третий - открытую героем истину о произошедшем; второй катрен описывает пассивный распад героя, заключительное двустишие - его новое активное действие.

Метрически Q 119 представляет собой пятистопный ямб, который играет роль своего рода рампы: его задача «отделять эстетическое событие от жизни» (Бахтин, 2003: 76) и формально свести все содержание к заданному им единству. Однако ритмически-интонационная структура сонета, естественно, пятистопником не предопределяется. Если метр всегда универсален, то интонация всегда индивидуальна и является выражением оценки, проникающей в предмет речи, точнее говоря, она и «создает образ предмета» (там же: 77). Как правило, интонация принадлежит герою произведения и выражает его реакцию на сообщаемое содержание. Эта реакция в Q 119 представляет собой, как уже отмечалось выше, потрясение от внезапного открытия истины и нового осознания героем самого себя. Ритмически Q 119 распадается на две части, причем границу разлома обозначает пауза, приходящаяся на середину 9-й строки: O benefit of ill! | now I find true («О благостыня зла!| я смог понять»). Ритмическая структура придает особую акцентировку отдельным звукам, на которые падает интонационное ударение, благодаря чему соответствующие слова приобретают дополнительный оттенок значения. Например, в звучании первых трех строк (What potions have I drunk of Siren tears, / Distilled from limbecks foul as hell within, / Applying fears to hopes, and hopes to fears...) у слова "hopes" ( «надежды») появляется дополнительное значение из-за интонационной выделенности звукового сходства с начальными словами сонета “what potions" («что за зелья»): здесь «надежда» приобретает значение «обманчивый мираж, порожденный дурманом». Во втором катрене заметно выделяется звукопись “е”: “wretched errors” ( «скверные ошибки»), “blessed never" («блаженным как никогда»), “fever” ( «лихорадка»), выражающая значение мнимо-иллюзорного лихорадочного счастья-зла; в третьем катрене - звукопись “u:" “true" («истина»), “ruined love” ( «разбитая любовь»), “апеw” ( «заново»), передающая чувство восстановления и обновления. Таким образом, сами по себе незначащие элементы приобретают смысл и способность выражать оценочное значение благодаря особым интонационным акцентам, обусловленным реакцией лирического героя на описываемые явления. В тексте Q 119 хорошо видно, как реалистическая реакция героя противостоит формальной реакции автора. На основе этих наблюдений мы можем составить себе представление об общей идее данного сонета (учитывая то обстоятельство, что этическипознавательно автор слит с героем): это идея благотворности потрясения, приведшего к открытию лучшего и к новому самоосмыслению.

\section{ПРОСТРАНСТВО И ВРЕМЯ В Q 119.}

СЮЖЕТ И ФАБУАА. СОБЫТИЕ

Теперь коснемся пространственно-временного строения сонета, которое также обусловлено внутренней речью, автокоммуникацией. Аля решения этой последней задачи потребуется ввести еще два рабочих понятия: сюжета и фабуль. Под фабулой мы будем понимать причинно-следственную и хронологическую последовательность событий (Томашевский, 1996: 179-180), где событие есть результат внешней или вну- 
тренней деятельности героя, а под сюжетом композиционно упорядоченную фабулу (там же: 180-181). В основе и того, и другого термина лежит понятие о событии, но рассматриваемом в разных аспектах. Как мы уже видели, общее содержание Q 119 заключается в осмыслении некоего редуцированного события из жизни автора (подлежащего), которое в фокусе лирического героя порождает новое, уже эстетизированное событие открытия истины о лучшем. Таким образом, мы фактически имеем дело с двумя разноплановыми событиями: внешним, на которое намекается, и внутренним (событием саморефлексии), которое нам непосредственно дано. В связи с этим при анализе было бы невозможно ограничиться только каким-нибудь одним понятием. Но оба введенных термина объединены одной формируемой ими категорией пространства-времени, поскольку факт совершения любого события предполагает его нахождение в определенном месте в определенный момент.

Целое пространство Q 119 - это пространство самосознания лирического героя. Однако иконически оно представлено в образе пространственно-зримого тела героя, которое то распадается на части под чуждым влиянием (в прошлом), то снова образует неразложимое самостоятельно-активное единство целого «я» (в настоящем). Этому пассивному распаду - активному соединению соответствует образ разбитой в прошлом любви, которая теперь становится еще прекраснее, сильнее и значительнее, чем была. Таким образом, в пространственном отношении перед нами явлено «я» героя: его телесный образ, обретающий тем большую зримость, чем больше он распадается (т. е. утрачивает самотождественность), и теряющий видимость при обратном процессе, но обретающий дополнительную целостность за счет восстановления своих разрушенных чувств и связей с другими (возврат героя к своей «отраде»). Следовательно, если внутреннее событие сонета - мысли и эмоции - локализованы в самосознании, то внешнее событие жизни автора, транслированное лирическому герою, локализовано в пространственных координатах внешнего же тела, которое становится тем более зримым, чем больше оно распадается, т. е. отчуждается от героя. Внешнее событие касается фактов внешнего поведения, которое, однако, реально оказывается пассивным восприятием; внутреннее событие представляет факт внутреннего обнаружения истины, но при этом является активным действием, заново оформляющим героя.

Времл Q 119 явственно организовано по прямой «прошлое - настоящее». Однако, поскольку в тексте сообщается о двух событиях в прошлом и настоящем, то время здесь в действительности удвоено по схеме: прошлое и настоящее внешнего события, прошлое и настоящее внутреннего события. Следовательно, в этих четырех временных моментах реально имеется не два, а четыре события. Чтобы установить, что они собой представляют, нужно построить фабулу Q 119, т. е. изложить все имеющееся там содержание в хронологической и причинно-следственной зависимости.

Как мы уже видели, сонет начинается с осознания прошлого поведения героя ( «что за зелья я выпил», «как мое сердце ошибалось» и т. д.), которому противопоставлено настоящее обнаружение истины о лучшем («mеперь я нахожу истину)». Это прошлое и настоящее сознания. Однако два эти момента опосредует некий вторгающийся между ними внешний импульс, толчок: произошло нечто, что стимулировало активность сознания. Это событие (логическое подлежащее) прямо не описано в тексте: оно редуцировано практически до полной паузы, обозначенной нами как эмоциональный перелом: O benefit of ill! | now I find true. «Время» этой паузы тоже настоящее, однако оно предшествует настоящему самого текста сонета, т. е. настоящему сознания. 
Последнее поэтому можно назвать настоящим продолженным: действия, начатые в нем, перетекают в будущее: «я возвращаюсь», «я обретаю». Однако нельзя сказать, что редуцированное переломное событие сонета совершенно не восстанавливается: ведь на него намекает весь текст. Оно реконструируется благодаря намекам на образ «разбитой» в прошлом и теперь «заново восстановленной любви», к которой возвращается «порицаемый» герой. На основе этих отсылок можно констатировать наличие в сонете еще одного вида времени: прошлого прошедшего, своего рода плюсквамперфекта. Очевидно, что некогда герой обладал «лучшей любовью», которая оказалось разбитой. Можно предположить, что разрушение «лучшего» чувства произошло под влиянием недавнего наваждения, конец которому положило нынешнее переломное событие, и вот теперь - в самый момент автокоммуникации - герой осознает свое поведение и признает истинность лучшего чувства благодаря услышанному порицанию: «порицаемый, я возвращаюсь к своей отраде». Учитывая то обстоятельство, что под «лучшим», «разбитой / восстановленной дюбовью» и «отрадой» подразумевается не только чувство, но и человек, его вызвавший, можно допустить, что переломным событием (т. е. искомым подлежащим) для Q 119 послужила, например, встреча автора с этим человеком и выслушанное от него порицание, выражающее неравнодушие и беспокойство.

Суммируя все сказанное, мы можем представить фабулу Q 119 с помощью четырехчастной временной шкалы:

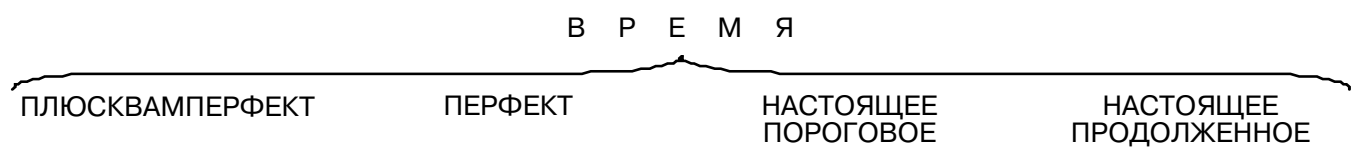

лучшая любовь

наваждение, лучшие чувства

внешне выраженный телесный распад «я» открытие истины и возврат к лучшему

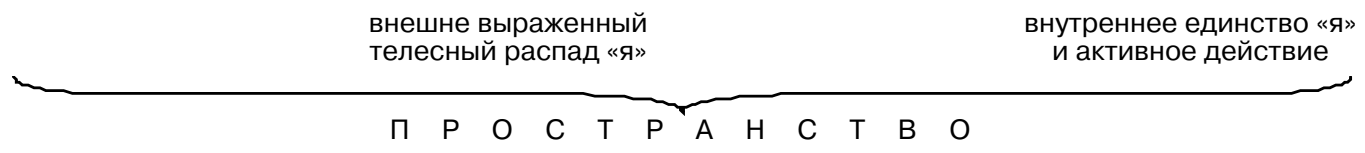

Сюжет Q 119 представляет собой ту же фабулу, но композиционно свернутую, причем композиция обусловлена точкой зрения лирического героя. Так, прошлое плюсквамперфекта в сюжете сокращено до беглого воспоминания, а пороговое переломное событие выпущено полностью. Явная пространственная выраженность соответствует только моментам сюжета, а не фабулы.

\section{ОСОБЕННОСТИ АВТОКОММУНИКАЦИИ ВО ВСТУПИТЕАЬНОМ ОБРАЗЕ Q 119}

Теперь, чтобы завершить анализ, стоит обратиться к вступительному образу сонета. Он сразу привлекает к себе внимание благодаря одному неожиданному обстоятельству: странному сбою в своей логической структуре. «Кажется, еще никто не указывал, насколько странно начало 119-го сонета Шекспира», - писала К. АанканАжоунз в посвященной этому образу статье (Duncan-Jones, 1997: 56; пер. наш. B. Ф.). Это сложная развернутая метафора: potions of Siren tears, distilled from limbecks foul as bell within («зелья из слез Сирены, нацеженные из перегонных кубов, 
мерзостных, как ад изнутри»). Весь образ сфокусирован на представлении о «слезах Сирены», и именно это обстоятельство прежде всего привлекает к себе внимание.

Сирены - полуженщины-полуптицы, пением завлекающие моряков к скалам, где последние неминуемо должны разбиться. Однако европейское сознание связало сирен с местом их обитания, и поэтому в дальнейшем они стали отождествляться с русалками - полуженщинами-полурыбами, также завлекающими моряков пением к гибельным местам. В любом обличье сирены воплощают собой представление о зле как о роковой разнице между внешним и внутренним: магнетизм их красоты и чудесного голоса фатально не соответствует их злобной иррациональной сути. В шекспировскую эпоху слово «сирены» обычно использовалось в прямом значении, т. е. как указание на особый род мифологических существ, однако его первое метафорическое употребление в Англии было зафиксировано уже в 1568 г. (согласно словарю Уэбстера; см.: Merriam-Webster's collegiate dictionary, 2004: 1165). В переносном смысле слово «сирена» указывает на обольстительную обманщицу, влекущую к погибели. Шекспировский образ ( «зелья из слез Сирены») явно подразумевает использование не прямого, а метафорического значения, а его введение показывает, что злое наваждение, описанное в первых двух катренах Q 119, возможно, было вызвано влиянием женщины, внешняя притягательность которой не соответствует ее отвратительной сути. Иначе говоря, она, как Сирена, одновременно прекрасна и мерзостна. В этом случае вполне вероятно, что Q 119 тесно связан с той частью шекспировского цикла, которая посвящена Смуглой даме. Fair («прекрасное») и foul («мерзостное») - ее постоянные эпитеты. И действительно, о связи со Смуглой дамой говорит использование внутри вступительного образа эпитета foul ( «мерзостный»), вообще не употребляемого в сонетах к Прекрасному другу, и общее описание состояния лирического героя, аналогичное его состоянию, описанному в тематически близком Q 147. В обоих стихотворениях герой характеризует свое поведение как болезненное безумие или как лихорадку, которая погружает его в мир мнимостей.

Таким образом, слово «Сирена» - это своего рода маркер, помечающий присутствие в тексте дополнительного смысла, который прямо не раскрыт, но подразумевается и одинаково ясен и автору, и лирическому герою. Текст здесь понятен лишь тому, кто «знает его заранее» (Иотман, 1996: 32), т. е. самому осмысляющему себя субъекту. Однако содержание вступительного образа этим далеко не исчерпывается уже потому, что он более распространен.

Шекспир говорит не просто о Сирене, а о слезах Сирены, и не просто о слезах, а о зельях, изготовленных из этих слез в перегонном кубе. Здесь и обнаруживается тот логический сбой, о котором упоминалось выше. Сирены поют, но они не плачут. Их колдовское воздействие на людей обеспечивается влиянием голоса, а не слез. Поэтому возникает некая необъяснимая внутренним содержанием стихотворения несообразность: откуда же взялись эти слезы Сирены и как они угодили в перегонный куб?

Вопрос этот возникает именно потому, что Q 119 представляет собой автокоммуникацию. Здесь перед нами вновь появляется уже виденный нами феномен редукции, «сворачивания» содержания мысли в сложносоставное единство. Все переходы и ментальные операции при этом опущены, поскольку субъект и так знает подлежащее своего образа. Противопоставляя речь внешнюю и внутреннюю, $\Lambda$. С. Выготский писал: «Внешняя речь есть процесс превращения мысли в слова, ее материализация и объективация. Здесь обратный по направлению процесс, идущий извне внутрь, процесс испарения речи в мысль» (Выготский, 1934: 279). Поэтому для внутренней речи 
вообще и для автокоммуникации в частности характерно «преобладание смысла слова над его значением» (там же: 305 ), т. е. слияние всех значений, словарных и контекстуальных, в одно синтетическое целое. Все ассоциации, которые во внешней речи потребовалось бы разложить, здесь сплетены в единый клубок.

Так, в образе «зелья из слез Сирены» можно увидеть двойную метонимию и одно метафорическое уподобление. Метонимия в данном случае является средством формирования образа слез. Ведь сирены - морские существа, живущие в воде; они нерасторжимо связаны с водной стихией, влагой, которая метонимически могла быть трансформирована в образ внутренне присущей существам влаги, т. е. в образ слез. Аналогично колдовское очарование голоса сирен метонимически же могло быть перенесено на другой их элемент. Метафора или, точнее, метафорическое уподобление послужило для образования связи между созданным представлением о «слезах» и образом «зелий из перегонного куба». Известно, что алкоголь при возгонке конденсируется именно каплями - «слезами». Слово limbeck (кроме Q 119) встречается у Шекспира только в «Макбете», причем именно в значении «аппарат для изготовления алкоголя»:

Я подпою вином и крепкой брагой

Обоих слуг его, чтоб стала память,

Привратница в дворце рассудка, паром,

А сам рассудок - перегонным кубом

(I, 7; пер. Ю. Б. Корнеева; цит. по: Шекспир, 1960: 25).

Предположение, что limbeck намекает на растворы алхимика, не вполне адекватно, поскольку в тексте сказано, что лирический герой выпил полученное после перегонки зелье, и его действие было сродни хмелю.

Обобщая все сказанное, можно представить структуру вступительного образа Q 119 в виде следующей схемы:

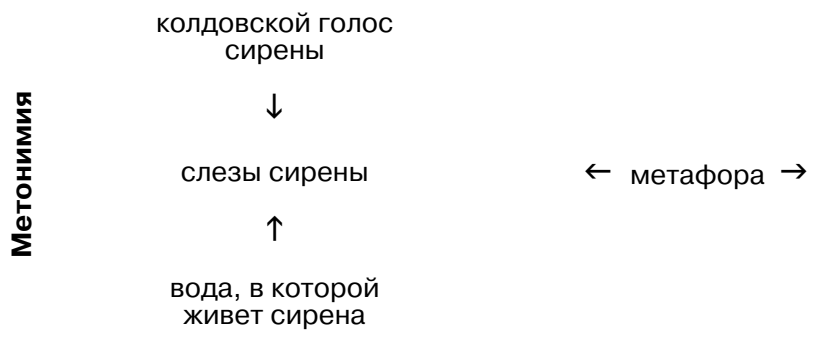

капли, оседающие на стенках перегонного куба

Очевидно, что структурным центром вступительного образа является уподобление слез Сирены каплям зелья. Однако столь же очевидно, что эта основная ассоциация возникла не в результате естественного развития темы неразумного поведения героя, а наоборот, явилась порождающей основой для именно такой трактовки темы. Поэтому причину возникновения этой ассоциации нужно искать вне текста - она находится за рамками его непосредственного содержания. Что это за причина, разумеется, можно только гадать. В заключение рискнем привести свою гипотезу.

Согласно нашему предположению, вступительный образ Q 119 может иметь чисто зрительное происхождение. В этом случае он указывает на место написания стихотворения (или на место состоявшейся у поэта встречи). В шекспировское время в цен- 
тре салка»; русские переводчики часто переводят его как «Сирена»), где собиралась тогдашняя литературно-театральная богема: эти собрания описаны $\Phi$. Бомонтом в стихотворении «Письмо Фрэнсиса Бомонта к Бену Ажонсону», написанном около 1615 г. (см.: Beaumont, 1750). Вывеска этого заведения, скорее всего, представляла собой изображение русалки, плавающей в пивной бочке (не исключено, что из ее крана капало пиво или эль). Возможно, что эта вывеска находилась перед глазами Шекспира незадолго до (или даже во время) написания сонета, и на основе впечатления от этого зрительного образа у поэта сформировалась ассоциация «Сирена / зелья» («ее слезы / их капли»), где слово «Сирена» служило метафорическим намеком на реальную женщину, а «зелья» - метафорическим именованием ее воздействия (одурманивание) на автобиографического героя. Эта ассоциация, в свою очередь, явилась порождающим тему наваждения образом первых двух катренов Q 119. Однако, разумеется, все это объяснение допустимо только в качестве гипотезы.

\section{ЗАКАЮЧЕНИЕ}

Подведем итоги. Можно констатировать, что текст Q 119 является автокоммуникацией и отличается следующими особенностями:

- рефлексия в сонете подавляет сообщение;

- сообщение редуцируется до намека, простой отсылки к памяти;

- логическое подлежащее (текущая ситуация, «пороговое время») при этом опускается;

- происходит ценностная переориентация героя.

Особенно ярко характерные черты автокоммуникации проявляются во вступительном образе сонета: множество задействованных в нем значений словно бы «стягиваются» в один емкий комбинированный смысл, при этом основа образа (подлежащее) восстанавливается лишь гипотетически.

Можно отметить также, что, поскольку в Q 119 лирический герой слит с автором в моменте саморефлексии, толчком для которой послужила внешняя ситуация, не исключена существенная автобиографичность образа лирического героя. Однако при этом, поскольку внешняя ситуация потребовала своего перевода из индивидуальноличностного на эстетический уровень, можно предполагать ее художественную значимость для автора.

\section{ПРИМЕЧАНИЕ}

${ }^{1}$ Номер сонета предваряется значком Q (Quarto), что означает порядковый номер сонета, присвоенный ему по первой публикации в 1609 г.

\section{СПИСОК АИТЕРАТУРЫ}

Бахтин, М. М. (2003) Собр. соч. : в 7 т. М. : Русские словари ; Языки славянской культуры. Т. 1: Философская эстетика 1920-х гг. 957 с.

Выготский, $\Lambda$. С. (1934) Мышление и речь : психологические исследования. М. ; $\Lambda$. : Гос. социально-экономическое изА-во. 324 с.

Ковтунова, И. И. (1986) Поэтическая речь как форма коммуникации // Вопросы языкознания. № 1. С. 3-13.

Иотман, Ю. М. (1996) Внутри мыслящих миров. Человек - текст - семиосфера — история. М. : Языки славянской культуры. 464 с.

Томашевский, В. Б. (1996) Теория литературы. Поэтика : учеб. пособие. М. : Аспект Пресс. $334 \mathrm{c.}$ 
Шекспир, У. (1960) Макбет / пер. Ю. Б. Корнеева // Шекспир, У. Полн. собр. соч. : в 8 т. / под ред. А. А. Смирнова, А. А. Аникста. М. : Искусство. Т. 7.823 с. С. 3-100.

Beaumont, F. (1750) Mr. Francis Beaumont's Letter to Ben Johnson // The works of Mr. Francis Beaumont, and Mr. John Fletcher : in 10 vols. L. : Printed for J. and R. Tonson and S. Draper. Vol. 10. 565 p. P. 365-368.

Duncan-Jones, K. (1997) 'Syren teares': Enchantment or infection in Shakespeare's Sonnet 119 // The Review of English Studies. Vol. 48. No. 189. P. 56-60.

Merriam-Webster's collegiate dictionary (2004): Eleventh Edition. Springfield, MA : MerriamWebster, Inc. 40a, $1623 \mathrm{p}$.

Shakespeare, W. (2002) The complete sonnets and poems / ed. by C. Burrow. Oxford : Oxford University Press. ix, 750 p. (The Oxford Shakespeare).

Аата поступления: 15.02.2017 2.

\section{SHAKESPEARE'S SONNET 119 AS SELF-COMMUNICATIVE TEXT \\ V. S. FLOROVA \\ MOSCOW STATE UNIVERSITY OF EDUCATION}

The article presents a view upon W. Shakespeare's Sonnet 119 from the perspective of self-communication. The poetic word emerges in between self-directed speech, that is, the largely spontaneous inner speech, and speech directed outwards. A trait characteristic of self-communication is fully identical volume of the addresser's and the addressee's memory: that is, a text of this kind is not supposed to transmit any new information. Sonnet 119 , instead of telling a story of some event, performs a completely different function, that is, of interpretation, or, rather, re-interpretation of what is already well-known.

Therefore, another key characteristic follows - the presence of a specific type of reduction in the text. Self-communication is ostensibly fragmentary, incomplete, tending to omit the subject / theme. The event itself is not related, but the subject's new conclusions about himself are based on it and hint at it. L. S. Vygotsky called this aptness to omit the subject predication. Predication is linked, among other things, with the fact that no self-communication is self-conditioned: it always needs an external impetus creating a shift in the situation, which, however, in the self-directed speech remains beyond the spoken.

These characteristic traits of self-communication are quite explicit in the opening trope of Sonnet 119: the multiple meanings involved into it are somewhat concentrated in a single, concise, combined meaning, however the basis of the trope (the subject) can only be conjectured. The structure of the whole text is also determined by the situation of self-addressing: seemingly two-part, it is actually three-part, the key event of the text being omitted, reduced nearly to silence. The article offers the conclusion that reading Sonnet 119 as self-communication gives a better insight into its nature.

Keywords: W. Shakespeare; sonnet; self-communication; predication; lyric subject; author; event; plot; story; space; time

\section{REFERENCES}

Bakhtin, M. M. (2003) Sobranie socbinenii : in 7 vols. Moscow, Russkie slovari Publ. ; Iazyki slavianskoi kul'tury Publ. Vol. 1: Filosofskaia estetika 1920-kh gg. 957 p. (In Russ.).

Vygotsky, L. S. (1934). Myshlenie i rech'. Moscow ; Leningrad, Gosudarstvennoe sotsial'no-ekonomicheskoe izdatel'stvo. 324 p. (In Russ.).

Kovtunova, I. I. (1986) Poeticheskaia rech' kak forma kommunikatsii. Voprosy iazykoznaniia, no. 1, pp. 3-13. (In Russ.).

Lotman, Yu. M. (1996) Vnutri mysliashchikb mirov. Moscow, Iazyki slavianskoi kul'tury. 464 p. (In Russ.).

Tomashevsky, V. B. (1996) Teoriia literatury. Poetika: A study guide. Moscow, Aspekt Press Publ. 334 p. (In Russ.). 
Shakespeare, W. (1960) Makbet / transl. by Yu. B. Korneev. In: Shakespeare, W. Polnoe sobranie sochinenii : in 8 vols. / ed. by A. A. Smirnov and A. A. Anikst. Moscow, Iskusstvo Publ. Vol. 7. 823 p. Pp. 3-100. (In Russ.).

Beaumont, F. (1750) Mr. Francis Beaumont's Letter to Ben Johnson. In: The works of Mr. Francis Beaumont, and Mr. Jobn Fletcher : in 10 vols. London, Printed for J. and R. Tonson and S. Draper. Vol. 10.565 p. Pp. $365-368$.

Duncan-Jones, K. (1997) 'Syren teares': Enchantment or infection in Shakespeare's sonnet 119. The Review of English Studies, vol. 48, no. 189, pp. 56-60.

Merriam-Webster's collegiate dictionary (2004): Eleventh Edition. Springfield, MA, MerriamWebster, Inc. 40a, 1623 p.

Shakespeare, W. (2002) The complete sonnets and poems / ed. by C. Burrow. Oxford, Oxford University Press. ix, 750 p. (The Oxford Shakespeare).

Submission date: 15.02.2017.

Флорова Валерия Сергеевна - кандидат философских наук, доцент кафедры философии Московского педагогического государственного университета, член Шекспировской комиссии при Научном совете «История мировой культуры» Российской академии наук. Адрес: 119571, Россия, г. Москва, пр-т Вернадского, д. 88. Тел.: +7 (495) 438-17-26. Эл. адреc: vsflorova@rambler.ru

Florova Valeria Sergeyevna, Candidate of Philosophy, Associate Professor, Department of Philosophy, Moscow State University of Education (MSPU); Member, Shakespeare Committee, Russian Academy of Sciences. Postal address: 88 Vernadsky Prospekt, 119571 Moscow, Russian Federation. Tel.: +7 (495) 438-17-26. E-mail: vsflorova@rambler.ru 